Tjalling C. Koopmans Research Institute

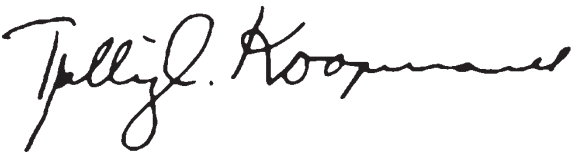

Discussion Paper Series nr: 07-06

\title{
Bargaining in Mergers and Termination Fees
}

Utz Weitzel, Stephanie Rosenkranz 


\section{Tjalling C. Koopmans Research Institute Utrecht School of Economics \\ Utrecht University}

Janskerkhof 12

3512 BL Utrecht

The Netherlands

telephone $\quad+31302539800$

fax $\quad+31302537373$

website www.koopmansinstitute.uu.nl

The Tjalling C. Koopmans Institute is the research institute and research school of Utrecht School of Economics.

It was founded in 2003, and named after Professor Tjalling C. Koopmans, Dutch-born Nobel Prize laureate in economics of 1975.

In the discussion papers series the Koopmans Institute publishes results of ongoing research for early dissemination of research results, and to enhance discussion with colleagues.

Please send any comments and suggestions on the Koopmans institute, or this series to s.mook@econ.uu.nl

ontwerp voorblad: WRIK Utrecht

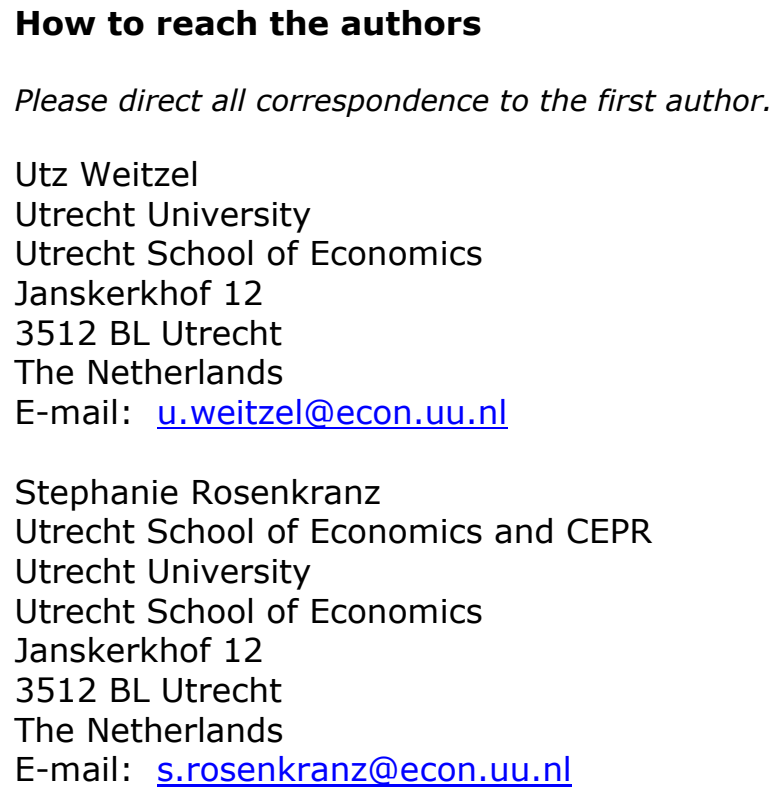

Please direct all correspondence to the first author.

Utz Weitzel

Utrecht University

Utrecht School of Economics

Janskerkhof 12

3512 BL Utrecht

The Netherlands

E-mail: u.weitzel@econ.uu.nl

Stephanie Rosenkranz

Utrecht School of Economics and CEPR

Utrecht University

Utrecht School of Economics

Janskerkhof 12

3512 BL Utrecht

The Netherlands

E-mail: s.rosenkranz@econ.uu.nl 
Utrecht School of Economics

Tjalling C. Koopmans Research Institute

Discussion Paper Series 07-06

\title{
Bargaining in Mergers and Termination Fees
}

\author{
Utz Weitzela \\ Stephanie Rosenkranz ${ }^{\mathrm{b}}$ \\ aUtrecht School of Economics \\ Utrecht University \\ bUtrecht School of Economics \\ Utrecht University \\ and CEPR
}

March 2007

\begin{abstract}
We model takeovers as a bargaining process and explain termination fees for, both, the target and the acquirer, subject to parties' bargaining power and outside options. In equilibrium, termination fees are offered by firms with outside options in exchange for a greater share of merger synergies. Termination fees decrease in firms' bargaining power, and increase in firms' outside options. We find that a merger with the second highest bidder, including a termination fee, can lead to equally high premiums as a merger with the highest bidder, without a termination fee. This novel result directly contrasts the agency cost perspective, which argues that termination provisions may be used by managers to lock into acquirers that do not generate the highest shareholder value. Further, even in a merger with the highest bidder and in the absence of bidding related costs, a termination fee is not necessarily a deal protection device, but can be used to improve shareholder value. Our bargaining model offers an alternative to auction related explanations of termination fees, like cost compensation or seller commitment.
\end{abstract}

Keywords: Mergers and Acquisitions, Bargaining, Outside Option, Termination Fees, Break-Up Fees, Lockups

JEL classification: G34, C71, C78, D44, K22

Acknowledgements

We thank Matthew Rhodes-Kropf, Frederik Schlingemann, Bart Lambrecht, Dennis Mueller, Rob Alessie, Thomas Gehrig, Gerhard Kling, and Jaap Bos for insightful comments and discussions. This paper also benefited from presentations at the MFA Annual Meeting (2006), the University of Amsterdam (2006), the GEABA Annual Meeting (2005), and the M\&A workshop at the University Utrecht (2004). Of course, all remaining errors are ours. An earlier draft of this paper was titled "Bargaining in Mergers: The Role of Outside Options and Termination Provisions". 


\section{Introduction}

Most mergers that are announced by public targets are based on a preliminary merger agreement, signed by the target management, that still has to be approved by the shareholders. Such agreements often include termination fees, payable by the target to the bidder in cash, in the event that the target cancels the agreement to accept a competing (bust-up) bid. ${ }^{1}$ In the last two decades Delaware courts repeatedly took a critical, but at times also a generous stance towards termination fees. ${ }^{2}$ The central question is why target managers voluntarily agree on termination fees, which inevitably lead to a decrease in shareholder value if the target accepts a bust-up bid. An agency related answer is that self-serving incumbent managers prefer side payments and entrenchment over shareholder value and thus use termination fees to lock into bidders who maximize their personal utility. This concern explains the significant judicial attention to termination fees in conjunction with alleged shareholder coercion and breach of target management's fiduciary duties. All the more so as termination fees are a popular contractual device in mergers and acquisitions. ${ }^{3}$

Contrasting the agency perspective, the current theoretical literature also offers shareholder oriented explanations for termination provisions. The cost compensation approach assumes that potential acquirers bear bidding-related direct costs or opportunity costs that decrease competition for the target unless these costs are taken account of in the form of termination fees. The commitment approach argues that termination fees increase the credibility of the target's claim that the winning bid will not be reneged, which can result in generally higher takeover premiums. Both of these approaches explain

\footnotetext{
${ }^{1}$ A similar contracting device are 'lockups' that grant the incumbent bidder a call option on the target's shares or assets, exercisable in the event that the target terminates the merger agreement. As both devices have very similar effects, we focus on the more straightforward case of termination fees.

${ }^{2}$ Prominent cases include Unocal Corp. v. Mesa Petroleum (493 A.2d 946 (Del. 1985)), Revlon Inc. v. MacAndrews \& Forbes Holdings (506 A.2d 173 (Del. 1986)), Paramount Communications Inc. v. QVC Network Inc (637 A.2d 34 (1993)), and Brazen v. Bell Atlantic (695 A.2d 43 (1997)).

${ }^{3}$ Depending on the sample and period of observation up to $79 \%$ of the analyzed merger agreements include termination fees and up to $29 \%$ include lockup options. See Boone and Mulherin (2007a), Bates and Lemmon (2003), Officer (2003), and Burch (2001).
} 
termination provisions within an auction setting.

Empirical testing whether termination provisions facilitate agency costs or shareholder value fails to offer unequivocal evidence. On the one hand, Coates and Subramanian (2000), Burch (2001), Officer (2003), and Bates and Lemmon (2003) find a positive association between target shareholder wealth and termination fees and/or lockup options, which contradicts agency cost related motives. On the other hand, the same studies also report that termination provisions are positively related to the probability of deal completion and negatively related to public takeover bidding. This can be interpreted as support for the agency cost approach and contradicts the auction-augmenting predictions of the cost compensation / commitment approach. The inconclusiveness of the empirical evidence may be partially explained by the use of incomplete or noisy data with regard to termination provisions (Boone and Mulherin 2007a) and premiums (Officer 2003). However, for another part the observed inconsistencies may also be due to the choice of an auction setting for the development of theoretical predictions.

In this paper we argue that the rather stylized assumptions of auction models may not always apply to takeover processes. We therefore advance an alternative model that explains the role of termination fees in a bargaining setup. For takeovers with only one bidder the choice of a bargaining setup is obvious. As Boone and Mulherin (2007b) show, targets often negotiate with only one interested party throughout the whole process, even when we take the non-public pre-annoucement phase into account. This applies to nearly $50 \%$ of the takeovers processes the authors have analyzed before and after the merger announcement until consummation. For takeovers with several bidders the case for a bargaining setup is less clear cut. In fact, these takeovers often appear to be textbook auctions: targets or their investment banks privately or publicly solicit bids from interested parties sometimes seem to conduct a sealed bid first price auction; tender offers and hostile takover bidding may resemble open bid second price auctions. However, despite many similarities, there exist a number of crucial conditions for auction modelling that are not always satisfied.

First, a central assumption in auction theory is that the seller will not renege a winning bid (McAfee and McMillan 1987). However, winning bids and merger agreements are often subject to shareholder approval. Target man- 
agers therefore often lack the necessary commitment power typically assumed in auctions, because the winning bid may not be approved and reneged by the shareholders themselves. Even if the target management could promise prohibitively high termination fees to exclude any renegotiation by the shareholders, this still does not guarantee that the target management herself will not renegotiate the winning bid before signing a merger agreement. As the seller always has the incentive to renege the outcome of an auction, the target management may first want to bargain with the winning bidder before signing the agreement. As a very prominent example for this, Klemperer (1998) cites the takeover battle for RJR Nabisco, which included several successive supposedly-final auctions for the company. Boone and Mulherin (2004) also quote an supposedly-final auction, where the target, Instron Corp, reneged the winning bid from Kirtland and solicited new offers from other potential buyers after conducting at least two rounds of first-price auctions. ${ }^{4}$ In their empirical analysis, Boone and Mulherin (2004) do not find any difference in target premiums between such auctions and one-to-one negotiations. We interpret this as support for our view that even when bidding takes place, potential acquirers anticipate that a merger agreement with the winning bidder may be subject to renegotiations. In principle, this equally applies when the target management is bypassed through shareholder agreements or tender offers, because renegotiation will also be in the interest of the target shareholder, unless she cares about the outcome of future deals (Povel and Singh 2006). Correspondingly, Comment and Jarrell (1987) report that four-fifths of all successful cash tender offers are (re)negotiated between bidders and target managers before expiration.

Second, asymmetric information between the seller and the bidders constitute an important condition for auctions. In fact, one of the reasons why a seller chooses an auction as selling mechanism is the fact that she has incomplete information about the reserve prices of the potential bidders. However, Cramton and Schwartz (1991) suggest that a target board sometimes conducts preliminary auctions to discover the identity as well as the valuation of the highest-valuing bidder and then negotiate individually with this bidder. ${ }^{5}$ In

\footnotetext{
${ }^{4}$ For more details on this bidding and negotiation process also refer to the DEFS14A SEC filing by Instron on July 23, 1999.

${ }^{5}$ Similar to our argument above, Cramton and Schwartz (1991) also conjecture that
} 
fact, in the above example of the acquisition of Instron Corp, interested bidders were invited to several rounds of more and more detailed valuations of the target, including a due diligence, after each of which the potential acquirers had to disclose their updated valuation in sealed bids (Boone and Mulherin 2004). As such measures are designed to effectively reduce asymmetric information between buyers and the seller, they work against pure auction settings and towards a bargaining mechanism.

Third, auction theory assumes that sellers (targets) have complete bargaining power, while acquirers have no bargaining power at all. By assuming this, the target is able to receive one-sided binding offers of the bidders, while the seller can freely break and accept higher offers until the auction ends. Although such a polarized distribution of bargaining power in favor of the target may sometimes exist, it does not necessarily apply to all mergers, especially when targets are in distress, face only one or very few interested bidders, or solicit to be acquired. The assumption of such a seller-polarized framework also makes it difficult to provide a coherent explanation for acquirer termination fees, which are often observed in combination with target termination fees. ${ }^{6}$

If any of the above three conditions is violated, a bargaining setting may be more suitable to model takeovers and the role of termination fees within this process. In fact, next to the present model there are a few other attempts to model mergers as bargaining processes. In line with our understanding of takeovers, but with a focus on non-contractible, synergy enhancing investments, Gilson and Schwartz (2005) and Hotchkiss, Qian, and Song (2005) model mergers and termination clauses in an incomplete contracting framework. Using a real options approach, Alvarez and Stenbacka (2006) analyze the relation between the bargaining power of the acquiring firm and takeover incentives, but without explicit focus on termination provisions.

The basic setup of our model is developed as follows. We start with a standard second price auction of a target and two bidders as a reference case. In this auction setting the target has (a) full bargaining power, (b) perfect commitment, and (c) asymmetric information over the bidders' valuations.

\footnotetext{
boards use termination fees to preserve their ability to conduct post-auction negotiations without discouraging entry in the preliminary auction.

${ }^{6}$ Hotchkiss, Qian, and Song (2005) find that in more than $20 \%$ of the deals they study, the acquirers agreed to pay termination fees to the target.
} 
Subsequently, we analyze the same situation with a bargaining setup, where the target does not necessarily have (a) full bargaining power, nor (b) perfect commitment, but (c) symmetric information. ${ }^{7}$ In this setup, a potential offer from the second bidder represents an outside option for the target in her negotiations with the first bidder. Conversely, any offer from the first bidder can be used by the target as a threat point (or, synonymously, disagreement payoff) in negotiations with the second bidder. Note that the offers are (still) only binding for the bidder, i.e. the target can break any offer without consequence at any time. We find that the equilibrium outcome of our bargaining model perfectly replicates the outcome of the auction reference case, i.e. the target always receives the valuation of the second highest bidder. This is independent of the parties' bargaining power in negotiations. Even with less bargaining power compared to auctions, the target can use her information about bidders' valuation to freely renegotiate any offer until the second price is reached. However, once we introduce the possibility of termination fees in merger contracts, early bidders can participate in the target's gain of using their signed offers as threat points towards bust-up acquirers. Some features of this mechanism are similar to auction models with cost compensation, where the target participates in the costs of early bidders. The termination fee can be interpreted as the price the target is willing to pay for receiving a higher bid. The crucial difference in our bargaining setup is, that here termination fees are determined by the target's marginal revenues and not by the bidder's marginal costs. The lower the target's bargaining power, in contrast to full bargaining power in the auction setting, the higher will be the price. In a sense, the target sells an option on potential bust-up gains in return for a threat point in the form of a signed merger agreement. By doing this, in equilibrium, the target is able to secure a higher premium. Analogously, acquirers that bargain with several potential targets may be able to get a higher share of joint synergies by offering a termination fee to the first target.

The main results of our model are as follows. Termination fees decrease in firms' bargaining power, and increase in firms' outside options. In equilibrium, termination fees are offered by firms with outside options in exchange for a

\footnotetext{
${ }^{7}$ We purposely do not assume any bidding- or negotiation-related costs. An inclusion of such costs would rather strengthen the qualitative results of our model.
} 
greater share of merger synergies. Thus, target termination fees that are higher than bidding-related costs incurred by the acquiring party can be in the interest of the target shareholders as they maximize their premium. Further, a merger with the second highest bidder, including a termination fee, can lead to equally high premiums as a merger with the highest bidder, without a termination fee. This novel result directly contrasts the management entrenchment perspective, which argues that termination provisions may be used by managers to lock into acquirers that do not generate the highest shareholder value. Further, even in a merger with the highest bidder and in the absence of bidding related costs, a termination fee is not necessarily a deal protection device, but can be used to improve shareholder value.

Our paper contributes to the primarily auction-related theoretical literature on termination fees. As a first contribution, we advance an alternative explanation in a bargaining setting, which we argue to be less restrictive and more applicable to the takeover process. Although our model is very simple, it is able to replicate many results of rather complex auction models with asymmetric bidders. As a second contribution, our model explains termination fees for both sides of the merger, i.e. for the target and for the acquirer. Although about $20 \%$ of mergers have either bilateral termination fees, or fees only payable by the acquirer (Hotchkiss, Qian, and Song 2005), the two sidedness of the issue is largely ignored. As a third and last contribution, the paper shows that even mergers that clearly appear to be a result of management entrenchment, i.e. mergers with the second highest bidder and with termination fees, are not necessarily detrimental for target shareholders. In fact, in equilibrium, the target can freely choose between the highest and the second highest bidder, because by offering a termination fee to the second highest bidder, the target is able to get the highest possible premium from both of them.

The paper proceeds as follows. Section 2 reviews the existing literature with regard to alternative explanations of termination fees, Section 3.2 describes the theoretical model and propositions, and Section 4 discusses implications and concludes. 


\section{Alternative explanations of termination fees}

The agency cost approach assumes that self-serving incumbent managers prefer side payments and entrenchment over shareholder value and thus choose a bidder who maximizes their personal utility function. Whenever the bidder with the highest side payments is not the most efficient bidder, the agency cost approach predicts that target managers agree on termination provisions in order to lock into the preferred partner, effectively foreclosing further bidding. Thus, according to the agency cost perspective, the pure existence of termination fees indicates that neither allocative efficiency nor target shareholder return is at its optimum. ${ }^{8}$

The cost compensation approach assumes that potential acquirers bear some sort of bidding-related direct cost or opportunity cost. ${ }^{9}$ If all valuations were common knowledge, only the most efficient bidder with the highest reservation price places a bid, while potential competitors quit immediately rather than participate in a costly but losing battle. Anticipating this the most efficient bidder could offer an infinitesimal amount above the target's market price and stay unchallenged. Starting from such a full-information model, Berkovitch and Khanna (1990) show that targets can employ takeover defenses for a discriminatory reduction of the highest reservation value, which 'levels the playing field' so that other bidders can also expect to win. Analogously, termination fees could be granted to lower valuation bidders. ${ }^{10}$ For sequential auctions, Hirshleifer and Png (1989) and Fishman (1988) demonstrate that bidding costs may cause weaker bidders to drop out of ascending English auctions prematurely. In a related setting, Kahan and Klausner (1996) point out that early bids may contain valuable information (e.g. about potential synergies) for subsequent bidders to free ride on. In both cases, termination

\footnotetext{
${ }^{8}$ See esp. Burch (2001), Coates and Subramanian (2000), Officer (2003), and Bates and Lemmon (2003) for a more detailed discussion and related tests.

${ }^{9}$ With regard to termination fees, opportunity costs seem to be more relevant since most merger agreements settle the reimbursement of direct expenses separately. These (mostly mutual) clauses encompass all verifiable out-of-pocket expenses related to the takeover, including fees for investment banks, legal advisors, and business consultants.

${ }^{10}$ Alternatively, a target could also directly compensate a lower valuation bidder for making a competing offer. Klemperer (1998) cites an example where Bell South was paid US $\$ 54$ million to enter a takeover battle for LIN broadcasting (original source: Economist, $15 / 6 / 1996$, p.83).
} 
fees could compensate for various bidding-related costs, effectively increasing bidding competition and improving the outcome.

The commitment approach states that termination provisions are used by the target to visibly and credibly bind itself to an auction outcome, because if potential acquirers conjecture that the target will renege a winning bid, they will put a discount on their bid. The choice of, and commitent to, an optimal auction design becomes crucial when bidders are asymmetric. ${ }^{11}$ Klemperer (1998) shows that the outcomes of standard ascending auctions are highly sensitive to small asymmetries between bidders and that this effect is greatly exacerbated by bidding-related costs. Povel and Singh (2004) and Povel and Singh (2006) propose a sequential auction as optimal selling mechanism to asymmetric bidders, where a target first offers an exclusive deal to the best informed bidder. Once a target has determined such an optimal auction mechanism, the announcement of termination fees for the winning bidder may signal the target's committment to the proposed selling procedure.

\section{The model}

\subsection{The auction as a reference case}

Consider a monopolistic target firm $T$ and two bidders (or potential buyers) $B_{i}$ with $i=1,2$. Suppose the target has incomplete information about the potential buyers' valuation $R_{i}$. The target could then invite bids from any interested buyer and conduct a (second-price or first-price) sealed-bid auction with reserve price $P$, which means that a bidder participating in the auction must at least bid $P$. If bidder $i$ does not win the auction, her utility is given by zero. If bidder $i$ wins the object and must pay the price $P_{i}$ according to the rules of the auction, then her utility is given by $R_{i}-P_{i}$. bidder $i$ 's type $R_{i}$ is the realization of a random variable $\widetilde{R}_{i}$. Each $\widetilde{R}_{i}$ is independently and identically distributed on the unit interval. While only bidder $i$ knows her realized value $R_{i}$, the other components of the model are assumed to be common knowledge. Each agent is interested in maximizing her expected payoff. Hence, our analysis is directly comparable with the standard model of the in-

\footnotetext{
${ }^{11}$ See Myerson (1981).
} 
dependent private values environment with symmetric bidders as analyzed by Riley and Samuelson (1981). ${ }^{12}$ If only one bidder participates, she wins and has to pay the reserve price $P$. It is well known that in the standard case, each bidder $i$ with $R_{i} \geq P$ will participate in the auction and bid her type $R_{i}$. In accordance with the revenue equivalence principle, in equilibrium, the target expects a payment that corresponds to the second-highest bid.

Essential for this result are two assumptions. It is assumed that the target has incomplete information over the bidders' valuations and that she has full bargaining power. If she would know the bidders' valuations, she would address the one with the highest valuation and, thanks to her full bargaining power, set a take-it-or-leave-it price equivalent to that valuation. It is further assumed that the target can commit herself to the auction mechanism, that a bid is binding in the sense that the bidder has to pay the price according to the rules of the auction in case there is no higher bid, and that bidding is costless. In the following, for simplicitly, we will refer to any price that is paid for the target as 'premium', and thus implicitly assume that the reserve price (stand alone value) of the target is zero.

\subsection{A bargaining model for mergers}

\subsubsection{One-sided binding contracts}

Now consider alternatively the following two-stage game. At the first stage a target firm $T$ and a bidder $B$ bargain over the division of the synergies $R_{1}$ form a potential merger. The target firm receives a premium of $P_{1}$ and the bidder receives $R_{1}-P_{1}$. At the second stage, one - or both - of the firms may have the opportunity to bargain with another merger partner. ${ }^{13}$ The possibility to merge at the second stage gives the firms an outside option at the first stage. The expected synergies from this alternative merger are denoted by $R_{2}^{B}$ if the bidder $B$ chooses her outside option, the expected synergies from the

\footnotetext{
${ }^{12}$ This model has been referred to as the "benchmark model" of auction theory in the survey article of McAfee and McMillan (1987).

${ }^{13}$ The more direct comparison to the auction framework would consider only a monopolistic target facing several buyers. As we are interested in a more general analysis, we consider the case where both firms may face competition.
} 
outside option of the target $T$ are $R_{2}^{T} \cdot{ }^{14}$ For simplicity, we assume that at the second stage there are no more outside options from future deals. Note that a player's decision to take up her outside option is a strategic decision. This distinguishes a player's outside option from her disagreement payoff (or threat point) that she would get if negotiations would end in disagreement or break down for some exogenous reason. Hence, at the second stage firms will come to a bargaining solution that is characterized by the "split the difference" principle, while the solution at the first stage will be characterized by the "outside option" principle. ${ }^{15}$ We assume that the bargaining process follows a simple alternating offers procedure in which the bargaining power of the target is denoted by $\lambda_{1}$.

Using backward induction we start by analysing the second stage to determine both party's outside options for the first stage negotiations. Consider the second stage in which the target $T$ bargains with an alternative merger partner. We assume that the threat point of the target firm is given by what she would receive as a premium from the merger with her first bargaining partner, hence, $d_{T}=P_{1}$. To make things interesting we assume that the second stage partners do not have any alternatives, hence $d_{B_{2}}=0 .{ }^{16}$ Applying the generalized Nash bargaining solution, the premium from this deal should be

$$
P_{2}^{T}=P_{1}+\lambda_{2}\left(R_{2}^{T}-P_{1}\right)
$$

\footnotetext{
${ }^{14}$ The model could be extended by allowing for renegotiations after the second stage bargaining. Under complete and perfect information this would not affect the results because the parties would correctly anticipate this possibility. However, in our model synergies at the second stage are in expected terms, which opens the opportunity for ex-post inefficiencies and thus incentives to renegotiate. In this case a renegotiation would still lead to qualitatively similar results. Based on our studies of existing merger contracts (SEC filings), we consider it reasonable to assume that parties do not write complex conditional contracts in this respect.

${ }^{15}$ According to Muttho (1999) the "split the difference" principle may be given the following interpretation: The parties bargain over the partition of $R$ and they first of all agree to give each other the utilites that they would, respectively, obtain from not reaching an agreement, and then the parties obtain a fraction $\lambda$, and $1-\lambda$ respectively, of the remaining utility. If the parties have outside options (which are in sum smaller than $R$ ), they may strategically opt out of negotiations. The outside option principle states that if one party's outside option exceeds her share from the "split the difference" principle, then her share is equal to her outside option.

${ }^{16}$ Alternatively, one could assume that the two partners at the second stage can also bargain with each other at the first stage. But this would cancel out possible effects form the second stage bargaining and make the entire problem completely dependend on the relative bargaining strength of the four firms.
} 
with $\lambda_{2}$ being the bargaining power of the target in the second stage.

Consider next the second stage for the case that the bidder $B$ bargains with an alternative merger partner. We assume that the threat point of the bidder is given by what she would receive as a synergies minus the premium from the merger with her first bargaining partner, hence, $d_{B}=R_{1}-P_{1}$. Again, we also assume that the second stage partner does not have any alternatives, hence $d_{T_{2}}=0$. Applying again the generalized Nash bargaining solution, the premium from this deal should be

$$
P_{2}^{B}=\widetilde{\lambda}_{2}\left(R_{2}^{B}-\left(R_{1}-P_{1}\right)\right)
$$

with $\widetilde{\lambda}_{2}$ being the bargaining power of the 'alternative' target, which represents the outside option of the bidder in the second stage.

For the case that the bidder terminates the merger agreement with the first stage target, she receives $R_{2}^{B}-P_{2}^{B}$ from the second stage merger if her first-stage agreement serves as a threat point.

Applying the outside option principle, we can now derive the premium at the first stage as follows:

$$
P_{1}=\left\{\begin{array}{clll}
\lambda_{1} R_{1} & \text { if } \quad P_{2}^{T} \leq \lambda_{1} R_{1} \quad \text { and } \quad R_{2}^{B}-P_{2}^{B} \leq\left(1-\lambda_{1}\right) R_{1} \\
P_{2}^{T} & \text { if } P_{2}^{T} \geq \lambda_{1} R_{1} \quad \text { and } \quad R_{2}^{B}-P_{2}^{B} \leq\left(1-\lambda_{1}\right) R_{1} \\
R_{1}-R_{2}^{B}+P_{2}^{B} & \text { if } P_{2}^{T} \leq \lambda_{1} R_{1} \quad \text { and } & R_{2}^{B}-P_{2}^{B}>\left(1-\lambda_{1}\right) R_{1}
\end{array}\right.
$$

In the first case, both parties' outside options are too low to be relevant for the outcome of the first-stage negotiations. In the second case, the target's second stage premium serves as a relevant outside option that directly determines the premium at the first stage, $P_{1}=P_{2}^{T}$ such that target is indifferent between the two deals. Substituting this into (1) leads to

$$
P_{2}^{T}=P_{2}^{T}+\lambda_{2}\left(R_{2}^{T}-P_{2}^{T}\right)
$$

Obviously, $P_{2}^{T}=R_{2}^{T}$ is the only solution to this equation, which implies that the target captures all gains of trade in the second stage negotiations. Analogously for the third case, in which the bidder's second stage outcome serves 
as a relevant outside option, we can derive

$$
\begin{aligned}
R_{2}^{B}-P_{2}^{B} & =R_{1}-\left(R_{1}-R_{2}^{B}+P_{2}^{B}\right)+\left(1-\widetilde{\lambda}_{2}\right)\left(R_{2}^{B}-\left(R_{1}-\left(R_{1}-R_{2}^{B}+P_{2}^{B}\right)\right)\right) \\
& \Leftrightarrow R_{2}^{B}-P_{2}^{B}=R_{2}^{B}-P_{2}^{B}+\left(1-\widetilde{\lambda}_{2}\right) P_{2}^{B} \\
& \Leftrightarrow P_{2}^{B}=0 .
\end{aligned}
$$

Note that the sequentiality drives our results here: Due to the fact that the second stage outcomes are perfectly anticipated in the first stage negotiations, the firms' outside options are endogenized at the first stage. During the negotiations today one of the firms, e.g., the target, may opt out strategically because negotiations tomorrow promise a higher premium. Of course, the bidder at the first stage will anticipate this and offer (a one-sided binding contract with) a premium that makes today's deal more attractive for the target. But even if the target signs the contract in agreement, it can still later break the deal and sign a second contract with bidder $B_{2}$. In the second stage negotiations the first stage premium serves as a threat point and thus helps the target to negotiate a better deal. The only offer bidder $B_{1}$ can make to prevent that the target will sign a contract with bidder $B_{2}$ is to offer exactly that premium that the target would get at the second stage when using the first stage premium as a threat point. We can summarize the above findings in the following proposition:

Proposition 1 The merger agreement will be signed at the first stage only if the first-stage deal generates the highest synergies. The merger contracts will be characterized by:

$$
P_{1}=\left\{\begin{array}{ccccc}
\lambda_{1} R_{1} & \text { if } & \lambda_{1} R_{1} \geq R_{2}^{T} & \text { and } & \left(1-\lambda_{1}\right) R_{1} \geq R_{2}^{B}, \\
R_{1}-R_{2}^{B} & \text { if } & \lambda_{1} R_{1} \geq R_{2}^{T} & \text { and } & R_{1} \geq R_{2}^{B}>\left(1-\lambda_{1}\right) R_{1} \\
R_{2}^{T} & \text { if } & R_{1} \geq R_{2}^{T} \geq \lambda_{1} R_{1} & \text { and } & \left(1-\lambda_{1}\right) R_{1} \geq R_{2}^{B} .
\end{array}\right.
$$

This result directly compares to the auction outcome: negotiations in this setting induce an agreement with that partner who has the highest evaluation (generates the highest synergies). If the target's outside option is relevant, the premium payed will correspond to the second highest evaluation. However, this result only holds as long as the agreement can be broken without consequence. In contrast to most publicly announced merger (pre-)contracts, this 
type of agreement rather resembles a preliminary term sheet, letter of intent, or memorandum of understanding. Although the parties agree upon an acquisition price (and other terms), their signature under such an agreement does not imply that they cannot sign another contract tomorrow. Commitment in this setting is very limited.

Note that whenever we additionally assume that the target not only has complete information about the bidders' evaluations but also has full bargaining power, $\lambda_{1}=1$, as in the auction setting, she would receive the complete synergies $R_{1}$, provided that the bidder has no relevant outside option. This obviously is the first-best scenario from the target's perspective.

\subsubsection{Binding contracts}

Now consider the situation in which at the first stage the firms will additionally bargain over a termination fee, that has to be payed in case that a party wants to take a higher offer after having signed a merger pre-contract. The party that decides to take the outside option after signing the first merger contract is required to pay this fee to the other party. We denote this termination fee as $T_{10}$ if it is paid from target firm $T$ to the bidder $B$, and $T_{01}$ if it is paid from $B$ to $T$.

Starting again with the target' second stage negotiations we have now to take into account that the 'gains of trade' from the potential merger at this stage are diminished by a potential termination fee $T_{10}$ that has to be paid to the first bidder. This implies a premium of:

$$
P_{2}^{T}=P_{1}+\lambda_{2}\left(R_{2}^{T}-P_{1}-T_{10}\right)
$$

At the first stage the two firms now simultaneously bargain over the premium as well as the termination fees, taking the possible outside option into account. While bargaining over the termination fees the firms distribute potential future benefits if one or the other firm terminates the contract. If the target terminates the contract, it receives $P_{2}^{T}$ form the second stage merger provided that it uses the first contract with $P_{1}$ as a threat point in the second stage negotiations. If the first stage negotiation ends in disagreement, there would be no threat point for the second stage negotiations which would then lead to a premium of $\tilde{P}_{2}=\lambda_{2} R_{2}^{T}$. The difference between those two outcomes 
represents the 'gains of trade' for the termination fee negotiation at the first stage. From this difference the target pays $T_{10}$ to the bidder. Given that both firms' disagreement payoffs are zero in this bargaining problem, the bidder receives:

$$
T_{10}=\left(1-\lambda_{1}\right)\left(P_{2}^{T}-\tilde{P}_{2}\right)
$$

Substituting (3) and solving this expression for $T_{10}$, we find:

$$
\begin{aligned}
T_{10} & =\left(1-\lambda_{1}\right)\left(P_{1}\left(1-\lambda_{2}\right)-\lambda_{2} T_{10}\right), \text { or } \\
T_{10} & =\frac{\left(1-\lambda_{1}\right)\left(1-\lambda_{2}\right) P_{1}}{1+\left(1-\lambda_{1}\right) \lambda_{2}}
\end{aligned}
$$

Consider next the second stage for the case that the bidder bargains with its alternative merger partner. As above, the 'gains of trade' from this merger are diminished by the termination fee $T_{01}$ that has to be paid to the first target. Applying again the generalized Nash bargaining solution, holding all other assumptions constant, the premium from this deal should be:

$$
P_{2}^{B}=\widetilde{\lambda}_{2}\left(R_{2}^{B}-\left(R_{1}-P_{1}\right)-T_{01}\right)
$$

For the case that the bidder terminates the contract, she receives $R_{2}^{B}-P_{2}^{B}$ from the second stage merger if her first-stage agreement serves as a threat point, while she would receive $R_{2}^{B}-\tilde{P}_{2}^{B}=\left(1-\tilde{\lambda}_{2}\right) R_{2}^{B}$ if she negotiates without a threat point. From this difference she pays $T_{01}$ to the target, thereby diminishing the gains of trade from the second stage merger. If both firms' disagreement payoffs are again zero in this bargaining problem we get:

$$
T_{01}=\lambda_{1}\left(\left(R_{2}^{B}-P_{2}^{B}\right)-T_{01}-\left(R_{2}^{B}-\tilde{P}_{2}^{B}\right)\right)
$$

Substituting (5) and solving this expression for $T_{01}$, we find:

$$
\begin{aligned}
T_{01} & =\lambda_{1}\left(R_{2}-\widetilde{\lambda}_{2}\left(R_{2}-\left(R_{1}-P_{1}\right)-T_{01}\right)-T_{01}-\left(1-\widetilde{\lambda}_{2}\right) R_{2}\right) \\
T_{01} & =\frac{\lambda_{1} \widetilde{\lambda}_{2}\left(R_{1}-P_{1}\right)}{1+\lambda_{1}\left(1-\widetilde{\lambda}_{2}\right)}
\end{aligned}
$$

Applying the outside-option principle for the bargaining over the premium in 
the first stage merger deal, we can describe the premium as:

$$
P_{1}=\left\{\begin{array}{cll}
\lambda_{1} R_{1} & \text { if } \quad P_{2}^{T} \leq \lambda_{1} R_{1} \quad \text { and } \quad R_{2}^{B}-P_{2}^{B} \leq\left(1-\lambda_{1}\right) R_{1} \\
P_{2}^{T} & \text { if } P_{2}^{T} \geq \lambda_{1} R_{1} \quad \text { and } \quad R_{2}^{B}-P_{2}^{B} \leq\left(1-\lambda_{1}\right) R_{1} \\
R_{1}-R_{2}^{B}+P_{2}^{B} & \text { if } \quad P_{2}^{T} \leq \lambda_{1} R_{1} \quad \text { and } \quad R_{2}^{B}-P_{2}^{B}>\left(1-\lambda_{1}\right) R_{1}
\end{array}\right.
$$

In the first case, both parties' outside options are again too low to be relevant for the outcome of the first-stage negotiations. In the second case, target $T$ has an outside option that is larger than what it would earn form the first deal under Nash bargaining, while the bidder does not have an alternative merger partner. In order for the target to be indifferent between the two deals the primium at the first stage is $P_{1}=P_{2}^{T}$. Substituting this into (4) and both into (3), and solving for $P_{2}^{T}$ leads to:

$$
P_{2}^{T}=\frac{\left(1+\lambda_{2}-\lambda_{2} \lambda_{1}\right) R_{2}^{T}}{2-\lambda_{1}}
$$

Anticipating this, the firms choose a target termination fee and a premium of:

$$
T_{10}=\frac{\left(1-\lambda_{2}\right)\left(1-\lambda_{1}\right) R_{2}^{T}}{2-\lambda_{1}} \quad \text { and } \quad P_{1}=P_{2}^{T}=\frac{\left(1+\lambda_{2}-\lambda_{2} \lambda_{1}\right) R_{2}^{T}}{2-\lambda_{1}}
$$

Of course, this is only a valid outcome if in fact $R_{1}-P_{1} \geq 0$ and also $P_{2}^{T} \geq \lambda_{1} R_{1}$ hold. Hence, for this solution we have to assume the following relation between the synergies of the two deals:

$$
\frac{\lambda_{1}\left(2-\lambda_{1}\right)}{\left(1+\lambda_{2}-\lambda_{2} \lambda_{1}\right)} R_{1} \equiv A \leq R_{2}^{T} \leq B \equiv \frac{2-\lambda_{1}}{\left(1+\lambda_{2}-\lambda_{2} \lambda_{1}\right)} R_{1}
$$

Now suppose that the bidder $B$ has an outside option that is larger than what she would earn form the first deal under Nash bargaining, while the target has no such outside option. The premium would then be given by $P_{1}=R_{1}-R_{2}^{B}+P_{2}^{B}$. Substituting this into the second stage bargaining outcome (5) this would imply:

$$
\begin{aligned}
R_{2}-P_{2} & =R_{1}-P_{1}+\left(1-\widetilde{\lambda}_{2}\right)\left(R_{2}-\left(R_{1}-P_{1}\right)-T_{01}\right) \\
& =R_{1}-\left(R_{1}-R_{2}+P_{2}\right)+\left(1-\widetilde{\lambda}_{2}\right)\left(R_{2}-\left(R_{1}-\left(R_{1}-R_{2}+P_{2}\right)\right)-T_{01}\right) \\
& =R_{2}-P_{2}+\left(1-\widetilde{\lambda}_{2}\right)\left(P_{2}-T_{01}\right)
\end{aligned}
$$


which is only satisfied with $P_{2}=T_{01}$. Substituting both, first stage and second stage premium into (6) and solving for $T_{01}$ yields:

$$
T_{01}=\frac{\lambda_{1} \widetilde{\lambda}_{2} R_{2}^{B}}{\lambda_{1}+1}
$$

Hence, in equilibrium the firms choose an acquirer termination fee and a premium of:

$$
T_{01}=\frac{\lambda_{1} \widetilde{\lambda}_{2} R_{2}^{B}}{\lambda_{1}+1}=P_{2}^{B} \quad \text { and } \quad P_{1}=R_{1}-\frac{\left(1+\lambda_{1}-\lambda_{1} \widetilde{\lambda}_{2}\right)}{1+\lambda_{1}} R_{2}^{B}
$$

Of course, this is only a valid outcome if in fact $P_{1} \geq 0$ and also $R_{2}^{B}-P_{2}^{B}>$ $\left(1-\lambda_{1}\right) R_{1}$ hold. Hence, for this solution we have to assume the following relation between the synergies of the two deals:

$$
\frac{\left(1-\lambda_{1}\right)\left(\lambda_{1}+1\right)}{\left(1+\lambda_{1}-\lambda_{1} \widetilde{\lambda}_{2}\right)} R_{1} \equiv C \leq R_{2}^{B} \leq D \equiv \frac{\lambda_{1}+1}{\left(1+\lambda_{1}-\lambda_{1} \widetilde{\lambda}_{2}\right)} R_{1} .
$$

Hence, now we can conclude the following result.

Proposition 2 The contracts will be characterized by

i) a premium of $P_{1}=\lambda_{1} R_{1}$, and termination fees of $0 \leq T_{01} \leq \frac{\lambda_{1} \widetilde{\lambda}_{2} R_{2}^{B}}{1+\lambda_{1}}$ and $0 \leq T_{10} \leq \frac{\left(1-\lambda_{2}\right)\left(1-\lambda_{1}\right) R_{2}^{T}}{2-\lambda_{1}}$ if $R_{2}^{T} \leq A$ and $R_{2}^{B} \leq C$. The negotiations will not reach the second stage, hence, $P_{2}^{T}=P_{2}^{B}=0$,

ii) payments specified by (10) at the first stage and by (??) at the second stage if $R_{2}^{B}<C$ and $A<R_{2}^{T}<B$; and

iii) payments specified by (8) at the first stage and by (??) at the second stage if $C<R_{2}^{B}<D$ and $R_{2}^{T}<A$.

iv) There will be no contract at the first stage if $C<R_{2}^{B}$ and $A<R_{2}^{T}$ or if $D>R_{2}^{B}$ and/or $B>R_{2}^{T}$.

Proof. See the arguments above.

It is interesting to note that the bargaining partner on the second stage will not gain anything from the deal in case that the first stage firms come to an agreement. The gains of trade on that stage are completely absorbed by the two first stage firms: The second stage firm is confronted with a partner with a high disagreement point (the first stage premium) and obligations due 
to the termination fee. ${ }^{17}$

The proposition states that we need to distinguish three different regions, as exemplified in Figure1 (target's perspective) for $\lambda_{1}=\lambda_{2}=\widetilde{\lambda}_{2}=\frac{1}{2}$ and $R_{2}^{B}=0$. Part (i) of the proposition considers the case in which the outside option for both firms are rather low in comparison to the synergies of the deal. In this Region 1 the premium is determined by the firms' relative bargaining power. Firms may agree on symmetric or asymmetric termination fees although they do not influence allocative efficiency or bid outcomes. ${ }^{18}$ Part (ii) and (iii) of the proposition define Region 2 in which one of the firms has a relevant outside option, while the other has not. Here the premium is determined by this relevant outside option and a termination fee is fixed that is paid to the firm that has no outside option. Finally, in Region 3, both firms' outside options are so attractive that no deal will be signed in the first stage.

\footnotetext{
${ }^{17}$ For illustrative reasons assume for the moment that $\lambda_{1}=\lambda_{2}=\widetilde{\lambda}_{2}=\frac{1}{2}$. This would lead to the following values for the payments: $P_{2}^{B}=\frac{1}{6} R_{2}^{B}, T_{01}=\frac{1}{6} R_{2}^{B}$ and $P_{1}=R_{1}-\frac{5}{6} R_{2}^{B}$ as specified in the contracts for the different regions defined by $C=\frac{3}{5} R_{1}$ and $D=\frac{6}{5} R_{1}$, given that the buyer has the relevant outside option in the sense of the proposition. Hence, the second stage target would get $\frac{1}{6}$ of the synergies, the buyer gets $\frac{5}{6}$, from which he pays $\frac{1}{6}$ to the first target, given that the synergies with the second target are at least larger than $\frac{3}{5}$ of the synergies with the first target but not larger than $\frac{6}{5}$, because otherwise the buyer would directly contact the second target without signing any contract with the first target. If the target's outside option is the relevant one, the payments are $P_{2}^{T}=\frac{5}{6} R_{2}^{T}$ and $T_{10}=\frac{1}{6} R_{2}^{T}$ and $P_{1}=\frac{5}{6} R_{2}^{T}$ and the regions for the synergies are $A=\frac{3}{5} R_{1}$ and $B=\frac{6}{5} R_{1}$.

${ }^{18}$ Unilateral or bilateral cost compensation may be a reason for (moderate) termination fees in this region. This is supported by the fact that some termination fees are payable in the absence of a bust-up bid. As noted by Officer (2003), this type of fee structure is most compatible with the cost compensation logic, since the target (and third parties) may free ride on private information revealed by the bidder before the cancellation.
} 

$\mathrm{R}_{2}$ (synergies deal 2,
outside option)

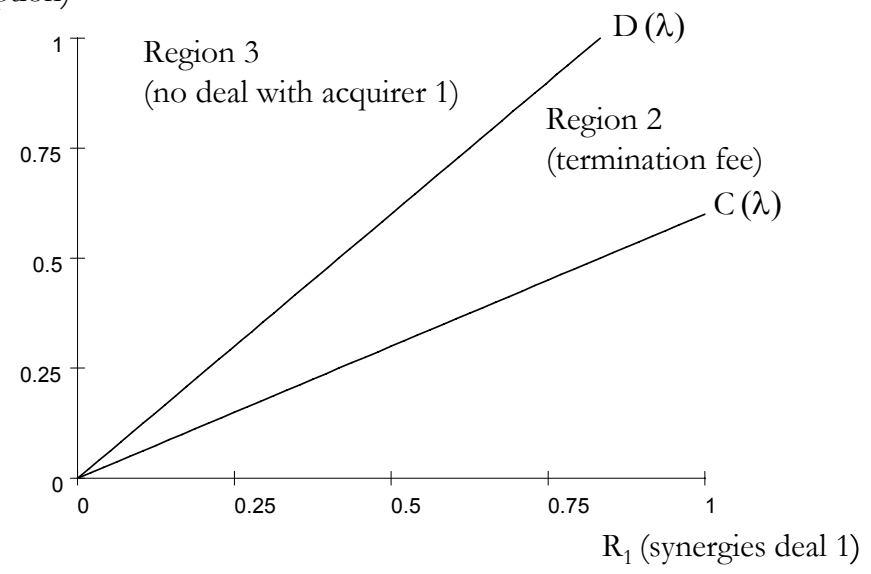

Regions defined by Proposition 1

For successful mergers (Region 1 and 2 in Figure 1) we can conclude that the larger the target's outside option $R_{2}$ for any given synergies $R_{1}$, the higher the likelihood that a termination fee will exist (i.e. that the deal will be positioned in Region 2). This is according to intuition since termination fees are only offered when the outside option is greater than the target's share of current synergies, determined by its bargaining power. In line with this, the comparative static properties of the functions $A(\lambda)$ (or $C(\lambda)$ ) and $B(\lambda)$ (or $D(\lambda)$ ) in the proposition reveal that Region 2 is reduced (enlarged) with an increase in the target's (acquirer's) bargaining power $\lambda$ (and $(1-\lambda)$ respectively). Thus, the likelihood of target termination arrangements decreases with a target's bargaining power.

As the following proposition shows, it is interesting to note that a termination fee will be included in the contract, even if the synergies of the merger under consideration are higher than the respective expected outside option's.

Proposition 3 The contract will include i) a target termination fee, even with the most efficient bidder, whenever $R_{2}^{B}<C$ and $A<R_{2}^{T}<R_{1}$, and ii) an acquirer termination fee, even with the most efficient target, whenever $C<R_{2}^{B}<R_{1}$ and $R_{2}^{T}<A$.

iii) Similarly, a contract including a target termination fee with a less efficient bidder will ensure the same (highest possible) premium for target shareholders as with the most efficient bidder, if $R_{2}^{B}<C$ and $R_{1}<R_{2}^{T}<B$. iv) Analogously, if $R_{1}<R_{2}^{B}<D$ and $R_{2}^{T}<A$, an acquirer termination fee with 
a less efficient target will also generate the highest possible share of synergies for the acquirer.

Proof. A comparison of the critical levels of synergies of the two deals, $A\left(\lambda_{1}, \lambda_{2}\right), B\left(\lambda_{1}, \lambda_{2}\right), C\left(\lambda_{1}, \widetilde{\lambda}_{2}\right)$, and $D\left(\lambda_{1}, \widetilde{\lambda}_{2}\right)$, with $R_{1}$ shows that $A\left(\lambda_{1}, \lambda_{2}\right) \leq$ $R_{1}, B\left(\lambda_{1}, \lambda_{2}\right) \geq R_{1}, C\left(\lambda_{1}, \widetilde{\lambda}_{2}\right) \leq R_{1}$, and $D\left(\lambda_{1}, \widetilde{\lambda}_{2}\right) \geq R_{1}, \forall \lambda_{1}, \widetilde{\lambda}_{2} \in[0,1]$. Result iii) and iv) are due to the fact that in equilibrium the target (respectively the bidder) must be indifferent between the deals at the two stages.

Finally, it is also interesting to note that the premium resulting from negotiations that include a target (acquirer) termination fee is lower (larger) than the premium in the previous setting, where bids and agreements were only one-sided binding. ${ }^{19}$ If the target has an attractive outside option it agrees to pay a termination fee to the acquirer to be able to breech the agreement. As the termination fee reduces tomorrow's gains of trade, tomorrow's premium will be lower and thus also the premium today. Following the same argument, the premium for the target today is larger if the bidder has a relevant outside option and agrees to a termination fee for the target.

For an intuition of these results, consider the following numerical example:

Assume that there are three firms, a target $T$ and two potential acquirers, bidder $B 1$ and bidder $B_{2}$. In case of a merger, $T$ and $B_{1}$ create synergies of 100 units, $T$ and $B_{2}$ create 90 units. For simplicity, suppose that all firms have the same bargaining power of $1 / 2$ and that the target negotiates first with $B_{1}$, taking into account that if negotiations are unsatisfactory she could opt out and approach $B_{2}$. Without the existence of an alternative bidder as an outside option, $T$ and could split the gains of trade and each get 50 units, $T$ and $B_{2}$ would each get 45 units of the synergies.

However, if $T$ would sign such a contract with $B_{1}$, it could use the premium of 50 units as a threat point in bust-up negotiations with $B_{2}$. $T$ would then receive 70 units from $B_{2}(50+40 * 1 / 2)$ and break the contract with $B_{1}$ at no additional cost. Thus, in comparison with having no contract with $B_{1}, T$ would gain an additional 25 units (70-45). In anticipation of enabling this, $B_{1}$ could negotiate a respective termination fee that corresponds with her bargaining power $(25 * 1 / 2)$ and match the premium of 70 units. Now, the gains of trade with $B_{2}$ are 7.5 units (90-82.5), which would still leave an incentive of $7.5^{*} 1 / 2$ for $T$ and $B_{2}$ to break a potential contract with $B_{1}$. Anticipating all this, $T$ is able to negotiate a $75: 25$ split of synergies with $B_{1}$ by offering a termination fee of 15 units $\left((75-45)^{*} 1 / 2\right)$ in return for an increased premium (from 50 to $75)$.

\footnotetext{
${ }^{19}$ This can be easily seen form $\frac{\left(1+\lambda_{2}-\lambda_{2} \lambda_{1}\right)}{2-\lambda_{1}} R_{2}^{T}<R_{2}^{T} \Leftrightarrow \frac{\left(1+\lambda_{2}-\lambda_{2} \lambda_{1}\right)}{2-\lambda_{1}}<1 \Leftrightarrow \lambda_{1}+$ $\lambda_{2}-\lambda_{2} \lambda_{1} \leq 1$ for the case that the target's outside option is relevant, and from $R_{1}-\frac{\left(1+\lambda_{1}-\lambda_{1} \widetilde{\lambda}_{2}\right)}{1+\lambda_{1}} R_{2}^{B}>R_{1}-R_{2}^{B} \Leftrightarrow \frac{\left(1+\lambda_{1}-\lambda_{1} \widetilde{\lambda}_{2}\right)}{1+\lambda_{1}}<1 \Leftrightarrow 1+\lambda_{1}-\lambda_{1} \widetilde{\lambda}_{2}<1+\lambda_{1}$ for the case that the buyer's outside option is relevant.
} 
In other words, target $T$ offers a termination fee so that it can use a signed contract with $B_{1}$ as a threat point in the negotiations with $B_{2}$, while possible negotiations with B2 serve as an outside option in the negotiations with $B_{1}$. Such a contract will be signed by the target and $B_{1}$ as long as the synergies with $B_{2}$ are not lower than 60 units and not higher than 120 units. In the former, the target can not use bidder $B_{2}$ as a viable outside option anymore, while in the latter a contract with $B_{1}$ does not serve the target as a viable threat point in negotiations with $B_{2}$.

\subsection{The effects of bargaining power and outside options}

If the negotiations are influenced by the outside option as in part (ii) to $(i v)$ of Proposition 2, the reduced forms in (8) and (10) show that both termination fees and the respective premia are functions of the relative bargaining power of the two firms, as well as of the value of the outside option. The larger the bargaining power of a target firm, the larger its share from the synergies. Moreover, the target firm is interested to pay a lower termination fee in case of contract breech.

In this setting the termination fee is the price for having a signed precontract that serves as a disagreement payoff (or threat point) in future negotiations. Since we assume - in contrast to the auction setting - (at least some) bargaining power on the side of the bidder, the price for this signature is determined by the marginal willingness-to-pay of the target. In an auction setting, where the bidder has no bargaining power, the price is determined by the marginal costs of the bidder (e.g. bidding costs). Assuming full bargaining power for the target, in our setting $\lambda_{1}=1$ would replicate this marginal cost pricing as it would lead to $T_{10}=c_{B}$, with $c_{B}=0$, as we assumed zero bidding costs.

Analyzing comparative static properties of (8) as well as (10) we can conclude the following two propositions:

Proposition 4 The target termination fee $T_{10}$ is a decreasing function of the target's bargaining power while the premium $P_{1}=P_{2}^{T}$ is an increasing function of the target's bargaining power (with the same absolute slope). The acquirer termination fee $T_{01}$ and the premium $P_{1}=P_{2}^{B}$ are both increasing functions of the target's bargaining power (with the same slope).

Proof. See the arguments in the appendix. 
Furthermore, we can consider the impact of differences in the firms' bargaining power in the deal under consideration and the bargaining power in the expected outside option negotiations. Analyzing comparative static properties of (8) as well as (10) with respect to the relative level of bargaining power in the two deals, we can furthermore conclude the following proposition:

Proposition 5 The larger the bargaining power of the target in the target's second stage negotiations, the lower will be the termination fee $T_{10}$ the target has to pay to the bidder. The lower the relative bargainig power of the bidder at the second stage negotiations, the higher is also the termination fee $T_{01}$ the acquirer has to pay to the target at the first stage.

Proof. See the arguments in the appendix.

An increase in bargaining power is beneficial. Interestingly, the result holds irrespective of whether bargaining power at the second stage negotiations is lower or higher (in absolute terms) than the bargaining power in first stage negotiations. Moreover, considering second-order derivatives shows that this effect is stronger the larger the bargaining power of the respective party in the first stage.

The effect of the value of the outside option on the negotiations is rather straightforward. Considering the case in which the target has an outside option, we see that the higher the outside option, the more likely will the firms agree upon a termination fee. Furthermore, the higher the outside option, the higher is also the termination fee. This property is summarized in the following proposition:

Proposition 6 The target termination fee $T_{10}$ as well as the premium $P_{1}=$ $P_{2}^{T}$ are increasing functions of the target's outside option $R_{2}^{T}$. The outside option has a stronger influence on the premium than on the target's termination fee.

Proof. See the arguments in the appendix.

Note that the model in principle allows for reciprocal termination fees, in the sense that the target termination fee $T_{10}$ as well as the acquirer termination fee $T_{01}$ have to be interpreted as the net payment from one firm to the other. 


\section{Implications and conclusion}

In contrast to existing approaches, we model takeovers as a bargaining process with termination fees. As a theoretical contribution, this allows us to explain the effect of termination fees in both directions: from the target to the acquirer and vice versa. In equilibrium, termination fees are accepted when they can be traded for a higher share of merger synergies, subject to firms' bargaining power and outside options. We can show that this even holds when the current bargaining partner represents the highest of all potential bidders and even when there are no bidding or contracting costs. Furthermore, we find that a merger with the second highest bidder, including a termination fee, can lead to an equally high premium as a merger with the highest bidder, without a termination fee. Our findings complement existing explanations of termination fees and suggest that bargaining effects should be considered as additional, maybe even substantial determinants.

Delaware courts have struggled to find a legal standard for termination provisions (Levy 2002). In re America West Airlines, Inc., the court rejected the business judgement rule in favor of the best interest standard. It reasoned that a termination fee would "not induce further bidding or bidding generally". As our analysis shows, this is no prerequisite since termination fees can still be used to increase prices, not only in the absence of an actual bust-up bid, but also when negotiating with the highest bidder. Even when bargaining with the second-highest bidder, since the target will not rationally sacrifice her outside option, an optimal net termination provision can extract maximum possible rents by rendering the highest bidder indifferent to making an offer. Thus, the absence of a bust-up bid might convey the impression of foreclosure, but does not necessarily harm target shareholders. In equilibrium, even termination fees with the second-highest bidder do not necessarily constitute a breach of fiduciary duties by target management.

These findings also challenge (i) the definition of 'preclusive' or 'coercive' in enhanced scrutiny approaches, as well as (ii) the definition of 'unfair and unreasonable' fees in the Hubb court factors. ${ }^{20}$ In Phelps Dodge Corp. v.

\footnotetext{
${ }^{20}$ Levy (2002) translated the Hubb seven-factor analysis for bankruptcy asset sales into the following test for takeovers: (i) Whether the fee correlates with the maximization of shareholder value; (ii) Whether the underlying negotiated agreement is an arms-length transaction
} 
Cyprus Amax Minerals Co. (No. 17398; Sept. 27, 1999), the Delaware Court of Chancery accepted a termination fee of $6.3 \%$ of the transaction value, but also stated that this "probably stretches the definition [of range of reasonableness] beyond its breaking point." Contrasting this with our model, armchair calculations suggest that fees of up to $\frac{1}{6}$ of the highest bid price can in principle be justified, provided that the target has duly considered all interested parties in the bargaining process (including the plaintiff) and that she has equal bargaining power.

In conclusion, we believe that there exists no exclusive theoretical explanation for termination fees in merger agreements or contracts in general. Certainly, only an unconditionally benign perception of managers would generally rule out agency costs as a possible motive. Also, the compensation of biddingrelated costs (as successfully argued in Brazen v. Bell Atlantic) as well as seller commitment might play a role in the negotiation of termination fees. However, when faced with a choice between a simple bargaining model and rather complex modifications of auction models as an underlying theoretical setting, we argue that the former is less restrictive and that it is more applicable to both sides of the merger as well as to the takeover process as such.

\footnotetext{
between merger partners; (iii) Whether the directors followed a reasonable decision-making process; (iv) Whether the fee constitutes a fair and reasonable percentage of the proposed purchase price; (v) Whether the dollar amount of the fee is so substantial that it deters or chills other potential bidders; (vi) Whether other provisions exist in the merger agreement that are detrimental to the shareholders; (vii) Whether there is a substantial adverse impact to shareholders' legal and statutory right to vote.
} 


\section{Appendix}

Proof of Proposition 4: Consider the following derivatives from equation (8):

$$
\begin{aligned}
\frac{\partial T_{10}}{\partial \lambda_{1}} & =\frac{\partial \frac{\left(1-\lambda_{2}\right)\left(1-\lambda_{1}\right) R_{2}^{T}}{2-\lambda_{1}}}{\partial \lambda_{1}}=\frac{\left(\lambda_{2}-1\right) R_{2}^{T}}{\left(\lambda_{1}-2\right)^{2}}<0 \quad \text { and } \\
\frac{\partial P_{1}}{\partial \lambda_{1}} & =\frac{\partial \frac{\left(1+\lambda_{2}-\lambda_{2} \lambda_{1}\right) R_{2}^{T}}{2-\lambda_{1}}}{\partial \lambda_{1}}=-\frac{\left(\lambda_{2}-1\right) R_{2}^{T}}{\left(\lambda_{1}-2\right)^{2}}>0,
\end{aligned}
$$

Where the inequalities hold due to $\lambda_{1}, \lambda_{2} \in[0,1]$. Consider the following derivatives from equation (10):

$$
\frac{\partial T_{01}}{\partial \lambda_{1}}=\frac{\partial P_{1}}{\partial \lambda_{1}}=\frac{\partial \frac{\lambda_{1} \widetilde{\lambda}_{2} R_{2}^{B}}{\lambda_{1}+1}}{\partial \lambda_{1}}=\frac{\widetilde{\lambda}_{2} R_{2}^{B}}{\left(\lambda_{1}+1\right)^{2}}>0
$$

Proof of Proposition 5: Assume $\widetilde{\lambda}_{2}=\alpha \lambda_{1}$, and $\lambda_{2}=\beta \lambda_{1}$. We can rewrite the fee in 8 to get:

$$
\begin{aligned}
T_{10} & =\frac{\left(1-\beta \lambda_{1}\right)\left(1-\lambda_{1}\right) R_{2}^{T}}{2-\lambda_{1}} \quad \text { and } \\
\frac{\partial T_{10}}{\partial \beta} & =\frac{R_{2}^{T}}{2-\lambda_{1}}\left(\lambda_{1}^{2}-\lambda_{1}\right)<0 \quad \forall \beta \in \mathbb{R} .
\end{aligned}
$$

Hence, the larger the relative bargainig power of the target in the expected outside-option negotiations, the lower will be the termination fee the target has to pay to the acquirer.

We can rewrite the fee in 10 to get:

$$
T_{01}=\frac{\lambda_{1} \alpha \lambda_{1} R_{2}^{B}}{\lambda_{1}+1}
$$

The larger the relative bargainig power of the outside-option target the higher is also the termination fee the acquirer has to pay:

$$
\frac{\partial T_{01}}{\partial \alpha}=\frac{\lambda_{1}^{2} R_{2}^{B}}{\lambda_{1}+1}>0 \quad \forall \quad \alpha \in \mathbb{R} .
$$


Moreover:

$$
\frac{\partial^{2} T_{01}}{\partial \alpha \partial \lambda_{1}}=\frac{\partial \frac{\lambda_{1}^{2} R_{2}^{B}}{\lambda_{1}+1}}{\partial \lambda_{1}}=\frac{\left(\lambda_{1}+2\right) R_{2}^{B} \lambda_{1}}{\left(\lambda_{1}+1\right)^{2}}>0 .
$$

Proof of Proposition 6: Consider the following derivatives from equations (8):

$$
\frac{\partial T_{10}}{\partial R_{2}^{T}}=\frac{\left(1-\lambda_{2}\right)\left(1-\lambda_{1}\right)}{2-\lambda_{1}}>0 \quad \text { and } \quad \frac{\partial P_{1}}{\partial R_{2}^{T}}=\frac{\left(1+\lambda_{2}-\lambda_{2} \lambda_{1}\right)}{2-\lambda_{1}}>0
$$

Obviously, the following holds:

$$
\frac{\partial T_{10}}{\partial R_{2}^{T}}-\frac{\partial P_{1}}{\partial R_{2}^{T}}=\frac{2 \lambda_{2}\left(\lambda_{1}-1\right)-\lambda_{1}}{2-\lambda_{1}}<0 \text { for all } \lambda_{1} \in[0,1] .
$$

Taking derivatives from equations (10) we can prove the acquirer's side analogously. 


\section{References}

Alvarez, L. H. R. and R. Stenbacka (2006). Takeover timing, implementation uncertainty, and embedded divestment options. Review of Finance 10(3), 417-441.

Bates, T. W. and M. L. Lemmon (2003). Breaking up is hard to do? an analysis of termination fee provisions and merger outcomes. Journal of Financial Economics 69, 469-504.

Berkovitch, E. and N. Khanna (1990). How target shareholders benefit from value-reducing defensive strategies in takeovers. The Journal of Finance 45, 137-156.

Boone, A. L. and J. H. Mulherin (2004). How are firms sold? Working paper, Claremont McKenna College.

Boone, A. L. and J. H. Mulherin (2007a, March). Do termination provisions truncate the takeover bidding process? Review of Financial Studies $20(2), 461-489$.

Boone, A. L. and J. H. Mulherin (2007b, forthcoming). How are firms sold. Journal of Finance.

Burch, T. R. (2001). Locking out rival bidders: The use of lockup options in corporate mergers. Journal of Financial Economics 60, 103-141.

Coates, J. C. and G. Subramanian (2000). A buy-side model of MA lockups: Theory and evidence. Stanford Law Review 53, 307-396.

Comment, R. and G. A. Jarrell (1987). Two-tier and negotiated tender offers: The imprisonment of the free-riding shareholder. Journal of Financial Economics 19, 283-310.

Cramton, P. and A. Schwartz (1991). Using auction theory to inform takeover regulation. Journal of Law, Economics, and Organization 7(1), $27-53$.

Fishman, M. J. (1988). A theory of preemptive takeover bidding. RAND Journal of Economics 19, 88-101.

Gilson, R. J. and A. Schwartz (2005). Understanding MACs: Moral hazard in acquisitions. Journal of Law, Economics, Organization 21(2), 330358. 
Hirshleifer, D. and I. P. L. Png (1989). Facilitation of competing bids and the price of takeover target. The Review of Financial Studies 2(4), 587-606.

Hotchkiss, E., J. Qian, and W. Song (2005). Holdups, renegotiation, and deal protection in mergers. SSRN Discussion Paper.

Kahan, M. and M. Klausner (1996). Lockups and the market for corporate control. Stanford Law Review 48, 1539-1571.

Klemperer, P. (1998). Auctions with almost common values: The 'wallet game' and its applications. European Economic Review 42, 757-769.

Levy, E. R. (2002). Corporate courtship gone sour: Applying a bankruptcy approach to termination fee provisions in merger and acquisition agreements. Hofstra Law Review 30, 1361-1402.

McAfee, R. and J. McMillan (1987). Auctions and bidding. The Journal of Economic Literature 25, 699-738.

Muttho, A. (1999). Bargaining Theory with Applications. Cambridge: UK: Cambridge University Press.

Myerson, R. B. (1981, Feb.). Optimal auction design. Mathematical Operations Research 6(1), 58-73.

Officer, M. S. (2003). Termination fees in mergers and acquisitions. Journal of Financial Economics 69, 431-467.

Povel, P. and R. Singh (2004). Using bidder asymmetry to increase seller revenue. Economics Letters 84, 17-20.

Povel, P. and R. Singh (2006). Takeover contests with asymmetric bidders. The Review of Financial Studies 19(4), 1399-1431. 